\title{
Treatment of hydatid cyst and bilio-bronchial and bilio-pleuro-bronchial fistulas via thoracotomy and transdiafragmal approach from October 2005 to October 2012 in a single unit in Tirana, Albania
}

\author{
F Gradica ${ }^{1 *}$, A Menzelxhiu $^{1}$, F Kokiqi ${ }^{2}$, E Fype ${ }^{2}$, A Cami ${ }^{2}$, E Shehu $^{3}$, D Argjiri ${ }^{3}$, P Kapisyzi ${ }^{3}$, I Skenduli ${ }^{1}$, F Caushi $^{1}$
}

From 23rd World Congress of the World Society of Cardio-Thoracic Surgeons

Split, Croatia. 12-15 September 2013

\section{Background}

The aim of this study was to report the results of surgical treatment of hydatid bilio-bronchial et bilio-pleurobronchial fistulas via thoracotomy and transdiafragmal approach.

\section{Methods}

From October 2005 to October 2012, 13 cases were observed in the same center. Biliptysis was the main symptom in $80 \%$ of cases. The diagnosis was based on chest radiography, thoracic and abdominal $\mathrm{CT}$ and abdominal ultrasonography, fibrobronchoscopy; all examinations visualised the cyst, intrathoracic collections, a diaphragmatic breach and biliary lesions. All patients were treated by one-stage thoracotomy. The procedures consisted of lung resection (lobectomy and/ or segmentectomy) $(\mathrm{n}=11)$ and decortication $(\mathrm{n}=6)$ in the chest, cyst dome resection $(n=13)$ or part pericystectomy $(\mathrm{n}=2)$ in the abdomen and suture and plastic of the diaphragmatic defect in all cases after hepatodiaphragmatic deconnection. An additional laparotomy was not necessary in all cases.

\section{Results}

There were 2 deaths (15.3\%): no one intraoperative death and two postoperative deaths, mostly related to pulmonary complications. Postoperative complications (14.3\%) were mainly respiratory. Clinical and radiological results were good with a one-year follow-up.

\section{Conclusions}

Bilio-bronchial and bilio-pleurobronchial fistulas due to hydatid cyst are rare, but severe diseases. They are responsible for lesions at three levels: abdominal, diaphragmatic and thoracic. A high perioperative mortality rate was observed. Thoracotomy with transdiafragmal approach is the best approach for surgical treatment at all three levels.

\section{Authors' details}

'Thorax Surgery Department, University Hosptal "Shefqet Ndroqi", Tirana, Albania. ${ }^{2}$ Anesthesiology and Reanimation Department, University Hosptal "Shefqet Ndroqi", Tirana, Albania. ${ }^{3}$ Pneumology Department, University Hosptal "Shefget Ndroqi", Tirana, Albania.

Published: 11 September 2013

doi:10.1186/1749-8090-8-S1-0257

Cite this article as: Gradica et al.: Treatment of hydatid cyst and biliobronchial and bilio-pleuro-bronchial fistulas via thoracotomy and transdiafragmal approach from October 2005 to October 2012 in a single unit in Tirana, Albania. Journal of Cardiothoracic Surgery 2013 8(Suppl 1): O257.

\footnotetext{
*Correspondence: fadilgradica@yahoo.com

"Thorax Surgery Department, University Hosptal "Shefget Ndroqi", Tirana, Albania

Full list of author information is available at the end of the article
} 